\title{
How Gendhing Gamelan reduced anxiety in pregnancy
}

\author{
Djohan 1 , Fortunata Tyasrinestu², Phakkharawat Sittiprapaporn ${ }^{3}$ \\ ${ }^{1}$ Professor, Graduate School of Indonesia Institute of the Arts Yogyakarta, Yogyakarta, Indonesia and Music \\ Performance Department, Indonesia Institute of the Arts Yogyakarta, Yogyakarta, Indonesia, ${ }^{2}$ Assistant Professor, \\ Music Education Department of Indonesia Institute of the Arts Yogyakarta, Yogyakarta, Indonesia, ${ }^{3}$ Assistant Professor \\ and Head, Brain Science and Engineering Innovation Research Group, School of Anti-Aging and Regenerative \\ Medicine, Mae Fah Luang University, Bangkok, Thailand and Department of Anti-Aging and Regenerative Science, \\ School of Anti-Aging and Regenerative Medicine, Mae Fah Luang University, Bangkok, Thailand
}

\section{A B S T R A C T}

Background: Listening to music will not only have a soothing and uplifting effects on someone but also a positive influence on the unborn baby. The positive vibes that will be acquired from listening to music will create a prenatal stimulation that will help pregnant mother to bond with their unborn baby. It will enable them to lower their stress and anxiety levels and also reduce any stress that the unborn baby may feel in the womb. Previous researches claimed the ability of music, especially western music, in reducing anxiety and stress toward pregnant woman. Aims and Objective: Instead of using western music, the present study investigated the effect of listening to gamelan music toward the reducing of anxiety on pregnancy. Materials and Methods: In a pilot experiment, 60 healthy volunteers (mean age $=29.0 ; \mathrm{SD}=5.0$ ) evaluated their anxiety responses to a Javanese traditional musical piece using a Slendro Sanga scale. Results: The research shows significant effect $(p<0.05 ; F=5.340)$ of Javanese traditional music to reduce anxiety in pregnant woman thus the hypotheses are accepted. Conclusion: Trust toward pregnant woman is important to be built because it can be the foundation of self-confidence and preventing stress. That is why, external situation is important since it has impact in internal situation.

Access this article online

Website:

http://nepjol.info/index.php/AJMS

DOI: 10.3126/ajms.v11i1.26517

E-ISSN: 2091-0576

P-ISSN: $2467-9100$

Key words: Stress reduction; Anxiety; Music listening

\section{INTRODUCTION}

Pregnancy period requires woman to have preparation physically and mentally due to physical and hormonal change that prone to generate anxiety. Biologically, the increasing of progesterone and estrogen will lead into easily exhausted and nausea. Psychologically, some women even feel depressed of the change and try to neglect the fact of their pregnancy. Physical changes, the anxiety because of physical changes, increasing of sexual desire but decreasing of libido, is need to be accepted by the environment. ${ }^{1}$ Unstable emotion is usually followed by mood changes such as being sensitive and overreacting with the result that the mental condition in vulnerable. This vulnerability might be caused by the gap between what is felt physically and what is understood mentally. Thus, pregnant woman tent to depend on other individual or being too demanding in this period. Another way to handle the discomfort during pregnancy is through the external factor that is one of human potency: music. Many attempts and research be done to help woman in facing pregnancy period. Research on Hye Sook Shin and Ju Hee Kim² showed significant decrease of stress and anxiety to a group of mothers that received 30-minutes music session out of health program. In another side, many transdisciplinary researches in humanities (music), social science (role), and natural science (medical) shows the role of music as media and way to enhance life quality. Further, music as a work of art or a product of internal and external experience is also representing human life empirically and contextually. Since music is inseparable from human life, its utilization needs to be developed further through supports in many sectors. 
Thus, this research aims to identify the effect of Gendbing Gamelan (Javanese traditional music) toward stress and anxiety reduction in pregnant women to discover its specific effects on psychological issue which are expected to support mental health in pregnant women that will implicate in fetus' mental health. We hypotheses (1) pregnant women be intervened by music will have less anxiety compare to control group, (2) pregnant women be intervened by music will have less stress compare to control group.

\section{MATERIALS AND METHODS}

\section{Design}

The design used in this research in non-equivalent control group non-synchronized as an attempt to discover the influence of Gending Gamelan listening to stress and anxiety reduction.

\section{Participants}

The subject in this research was determined incidentally. It consists of 60 women (experiment $=30$; control $=30$; mean age $=29.0 ; \mathrm{SD}=5.0)$ in Kotagede Society Health Center, Yogyakarta.

\section{Instruments}

\section{State trait anxiety inventory (STAI)}

State Trait Anxiety Inventory is a quick and short measurement of state and trait of anxiety to acquire high result for technical use. ${ }^{16}$ State anxiety is a temporary condition of fear or anxiety mainly experience in a particular event. Trait anxiety is a relatively stable tendency of a human to respond a stimulus in anxious way and prone to generate distress. Those two aspects seem different yet interrelated to one another. The level of trait anxiety reflects the inclination to show anxiety in human. STAI consists of 40 items to measure the two types of anxiety in separable way.

\section{Beck-depression inventory (BDI)}

Beck-Depression Inventory is a self-report rating inventory consisting of 21 items to measure characteristic attitude and symptoms of depression. This instrument is used as a control to strengthen the first instrument, STAI. Not only anxiety, previous research reported prevalence of depression among pregnant women ${ }^{17}$. We assume high level of anxiety will lead into depression. Thus, if the BDI index shows a decrease level, it might be assumed that the anxiety level is also decrease.

\section{Auditory stimuli}

The audio stimuli of this research are 15 minutes Gendhing Gamelan in slendro sanga scale that is heard by the subject through a wireless headset in a medium volume to make sure that the audio can be heard clearly but not too loud for the hearing.

\section{Procedure}

All subject is informed about the research and have consent to participate in this data collecting. After filling the pretest questionnaire, subjects are directed to the listening room. The experimenter needs to make sure the subjects are relaxed and comfortable during listening section thus the subjects are allowed to sit or nap on their own choice. The headset is installed under the consent of the subject considering their comfort. After listening the music for 15 minutes, we asked the subjects to fill the post test questionnaire.

\section{RESULTS}

To examine the effectiveness of the experiments, we present the condition of control and experiment group before treatment. The table above shows the minimum score of control group is 3 with maximum score 62 , meanwhile experiment group's minimum score is 3 with maximum score 64. Mean value of control group is 26.83 and mean value of experiment is 26.77 . Here we can see the higher mean of experiment group 0.06. To examine if both groups are similar to each other we applied a t test on SPSS for windows and the result is below.

Based on the t-test, both groups are considered homogenous if the significance coefficient $>0.05$. In contrast, if the significance $<0.05$ the sample of both groups is not homogenous. The result of t-test on Equal Variances Assumed column showed significance as big as 0.987 . Thus, both subject in control and experiment groups are homogenous and have similar anxiety level. The next table will present the score of control and experiment group after listening Gendhing Gamelan.

The data on table above shows the minimal score of control group is 5 and the maximum score is 55 . Meanwhile experiment group have minimal score of 3 and maximum score of 97. The mean value of control group is 27.33 and mean value of experiment group is 37.80 . The comparison above shows that experiment groups that listening to Gendhing Gamelan have better performance in reducing anxiety. This can be seen from the mean value increasing.

To do a different test using independent sample t-test, we need prerequisite test that are normality and homogeneity test. Normality test is needed to ascertain data distribution, whether it is normal or it isn't. Homogeneity test is needed to ascertain data homogeneity. Normality test is done with Shapiro-Wilk test on SPSS. The data is normally distributed if the significance coefficient $>0.05$. The data showed that Kolmogorov-Smirnov result that the posttest score of control group sig. 0.166 meanwhile experiment group sig. 
0.200. Both significance coefficient is $>0.05$ thus can be assumed that data in both groups is distributed normally. Homogeneity test is done by Levene Statistic test. The data is claimed to be homogeny if sig. $>0.05$. The result of homogeneity test with SPSS showed in the table below showed sig. value $0.378>0.05$ thus the posttest data is homogenous.

Independent sample t-test is used to ascribe the different on anxiety level between control and experiment group. These two group is considered different $\mathrm{f}$ the sig t-test for Equality of means $<0.05$. In contrast, if the value of sig. t-test for Equality of Means $>0.05$, both groups are assumed to me similar. The result of independent sample t-test is shown in table below. The t-test for Equality of Means on df 58 sig $0.024<0.05$. It can be considered that there is different level of anxiety of control and experiment group. The experiment group have lower anxiety level than control group. Here we can conclude that gamelan is enable to reduce anxiety in pregnant woman.

The comparison of control an experiment group score in pretest and post-test showed that mean value of control group without listening activity only increase 0.5 from 26.83 in pretest to 26.77 in posttest. Meanwhile the mean value of experiment group with listening activity increase 11.03 from 26.77 in pretest to 37.80 in posttest posttest (Table 1). It shows that control group without listening activity doesn't acquire significant effect of Gendhing Gamelan in reducing anxiety.

Further, to ascribe the effect of Gendhing Gamelan in reducing anxiety level in pregnant woman, we use One Way ANOVA. Through this analysis, we will examine the effect of independent variable, gamelan, in reducing anxiety as the dependent variable. In this analysis, independent variable is considered to take effect on dependent variable if it fulfilled two criteria: (1) F is bigger than F table and (2) sig. value $<0.05$. The One-way ANOVA result can be seen in table below:

The table above showed F 12.404 with sig. 0.001. In F table with df 58 sig. 0.05 we get $F$ table 4.01. The value of F 5.340 is bigger than F table 4.01. Moreover, the significance
$0.024<0.05$ (Table 2). Thus, we can conclude there is significant effect of listening to Gendhing Gamelan towards anxiety reduction in pregnant woman.

\section{DISCUSSION}

Statistical analysis above showed the relation of listening to Gendhing Gamelan and anxiety reduction in pregnant women. The result of homogeneity test showed that subject in experiment group tent to receive same effect from listening Javanese gamelan. Based on what happened in the data collection process, we found some respondent in experiment group that was not really focus and pay attention during music listening. Some of them broke the procedure of listening by playing their cellphone for a minute or two during the listening session. Another respondent came with their children and tent to less focus compared to the respondent without children because they had need to pay attention to their children. Some respondent seemed less enthusiast in answering posttest questionnaire and tent to answer fast without really try to make it sure. When the statistical analysis stated the homogeneity in experimental group in terms of listening and its ability to reduce anxiety, we need to discuss this result under the consideration of respondent different intention in doing the task. If in fact music listening need a proper focus and attention to gain the benefit, then what define the less focus respondents should be a rationale in criticize the instrument used to measure the anxiety or to reconsider whether self-report is proper enough to prevent random answer put by respondent in order to show difference before and after listening without really fell the difference in real. In other side, if the instrument can be confirmed effective to be used in this research design, we need to identify on how different listening attitude could lead into homogeny result.

In the perspective of anesthesia expert, music is claimed to be useful in C-section to strengthen anesthesia effect that is mostly without narcotics to make sure the infant won't be depressed. This labor preparation involving physical manipulation is prone to generate discomfort in mother thus music is believed to be effective in reducing

\section{Table 1: Descriptive statistics}

\begin{tabular}{lccc}
\hline Factors & Pretest score of control group & Pretest score of experiment group & Valid N (listwise) \\
\hline N & 30 & 30 & 30 \\
Range & 59 & 61 & \\
Minimum & 3 & 6 & \\
Maximum & 62 & 26.77 \\
Mean & 26.83 & 15.156 \\
Std. Deviation & 15.761 & 0.422 \\
Skewness & 0.222 & -0.103 \\
Kurtosis & -0.898 & & \\
\hline
\end{tabular}




\begin{tabular}{|c|c|c|c|c|c|}
\hline Factors & SS & df & $\begin{array}{l}\text { Mean } \\
\text { square }\end{array}$ & $F$ & Sig. \\
\hline $\begin{array}{l}\text { Between } \\
\text { groups }\end{array}$ & 1643.267 & 1 & 1643.267 & 5.340 & 0.024 \\
\hline $\begin{array}{l}\text { Within } \\
\text { groups }\end{array}$ & 17847.467 & 58 & 307.715 & & \\
\hline Total & 19490.733 & 59 & & & \\
\hline
\end{tabular}

the discomfort. In early pregnancy, stress overreacting creates a negative effect during pregnancy. Most of the physiological stress is mediated by stress hormonal named catecholamine. In pregnant woman, level of stress can reduce uterine contraction effectiveness ${ }^{3}$ and over anxiety is associated to fetal death in third trimester. ${ }^{4}$ Music is able to control respiratory rate and reduce stress response thus music can help to shorten the labor process. ${ }^{5}$ Another research suggests that music reduce pain when it is heard. ${ }^{6-7}$

Previous research also suggests on how majority young mother tent to hold their baby on their left chest, near by the heart. This intercultural phenomenon is assumed because the hearing ability the infants have since in the womb that it be the basic of musical potency in human. The research also suggests some similarities in music rhythm and rhythm infants hear in womb. ${ }^{8}$ The environment of prenatal period is also having its own impact toward fetus. Many physical stress and emotion during pregnancy will influence the abnormality in baby and inhibit the development of motoric function. ${ }^{9}$ In later pregnancy, most of fetus is able to listen their mother voice ${ }^{10}$ and some research stated that music is able to influence development of biological system. ${ }^{11}$ Further, listening to music is can improve learning ability, ${ }^{12}$ reduce bold pressure, and improve the epilepsy symptoms, Parkinson disease, and dementia. ${ }^{13}$ In contrast, noise generate a harmful environment and affect to animal pregnancy and its fetus. Noise is also associated to generate psychological and psychosomatic disease, such as, weight decreasing in newborn that lead to death, teratogens in fetus, as well as abortion. ${ }^{14}$ Likewise, the exposure of noise during pregnancy, it can disturb the brain development in baby and harm the cognitive function. ${ }^{15}$

To maintain the balance of chemical in pregnant woman, the there are four main hormone that mostly works; endorphin, dopamine, serotonin, and oxytocin that are contributing in positive feeling as a dimension of happy feeling. Dopamine and endorphin work as selfish chemical that is produced when someone is struggling to achieve something. Endorphin works by manipulate pain through happiness of euphoria. It happens for example when someone win a competition. Later, dopamine works by affecting the blood and generate a satisfaction. Meanwhile, serotonin and oxytocin are more external chemical that is generate a proud feeling because of being loved by a group or relatives such us parents, spouse, or children. Oxytocin works to promote empathy and trust, strengthen the bond between human to create a harmonious relationship. The more someone is being trusted or loved, the more oxytocin produced.

\section{CONCLUSION}

Here, the trust toward pregnant woman is important to be built because it can be the foundation of self-confidence and preventing stress. That is why, external situation is important since it has impact in internal situation.

\section{ACKNOWLEDGEMENT}

Foremost, we would like to express my sincere gratitude to the Ministry of Research, Technology, and Higher Education of Indonesia for the continuous support for this study and research. This research was partially supported by research funding from Brain Science and Engineering Innovation Research Group, Mae Fah Luang University grant (2019) (MFU-grant no. 611U109005) and 2020, Thailand. We thank all of the subjects involved in this research as main data provider of this studies.

\section{REFERENCES}

1 Shin H and Kim J. Music Therapy on Anxiety, Stress and Maternalfetal Attachment in Pregnant Women During Transvaginal Ultrasound. Asian Nursing Research 2011; 5: 19-27.

2. Simkin PT, Stress, pain, and catecholamines in labor: Part 1. A review. Birth. 1986; 13(4): 227-233.

3. Myers RE and Myers SE. Use of sedative, analgesic, and anesthetic drugs during labor and delivery: Bane or boon? American Journal of Obstetrics Gynecology 1979; 133: 83-104.

4. Winokur MA. The use of music as an audio-analgesia during childbirth. Unpublished master's thesis, The Florida State University, Tallahassee 1984.

5. McKinney $\mathrm{CH}$. Music therapy in obstetrics: A review. Music Therapy Perspectives 1990; 8: 57-60.

6. Hanser SB, Larson SC and O'Connell AS. The effect of music on relaxation of expectant mothers during labor. Journal of Music Therapy 1983; 20(2): 50-58.

7. Salk $L$. The role of the heart in the relations between mother and infant. Scientific American 1973; 228(5): 24-29.

8. Hayashi A, Nagaoka M, Yamada K, Ichitani Y, Miake Y and Okado N. Maternal stress induces synaptic loss and developmental disabilities of offspring. Int J Dev Neurosci 1998; 16: 209-216.

9. Lordi B, Patin V, Protais P, Mellier D and Caston J. Chronic stress in pregnant rats: effects on growth rate, anxiety and memory capabilities of the offspring. Int J Psychophysiol 2000; 37: 195-205.

10. Abbott A. Music, maestro, please!. Nature 2002; 416: 12-14.

11. Zatorre R and McGill J. Music, the food of neuroscience?. Nature 2005; 434: 312-315. 
12. Pacchetti $F$, Mancini $R$, Aglieri $C$, Fundaro E, Martignoni $E$ and Nappi G. Active music therapy in Parkinson's disease: an integrative method for motor and emotional rehabilitation. Psychosom. Med. 2000; 62: 386-393.

13. Turner RP. The acute effect of music on interictal epileptiform discharges. Epilepsy Behav 2004; 5: 662-668.

14. Williams MT, Hennessy MB and Davis HN. Stress during pregnancy alters rat offspring morphology and ultrasonic vocalizations. Physiol. Behav. 1998; 63: 337-343.

15. Spielberger CD. State-Trait Anxiety Inventory: Bibliography. ( $2^{\text {nd }}$ ed.). Palo Alto, CA: Consulting Psychologists Press, 1989.

16. Beck AT, Ward $\mathrm{CH}$, Mendelson $\mathrm{M}$, Mock $\mathrm{J}$ and Erbaugh $\mathrm{J}$. An inventory for measuring depression. Archives of General Psychiatry. 1961; 4: 561-571.

17. Young M. The Technical Writer's Handbook. Mill Valley, CA: University Science, 1989.

\section{Authors Contribution:}

D- Concept and design of the study, statistically analyzed and interpreted, manuscript preparation, critical revision of the manuscript; FT- Statistically analyzed and interpreted, manuscript preparation, critical revision of the manuscript, critical revision of the manuscript; PS- Manuscript preparation, critical revision of the manuscript, critical revision of the manuscript

\section{Work attributed to:}

Music Performance Department, Indonesia Institute of the Arts, Yogyakarta, Indonesia.

Music Education Department of Indonesia Institute of the Arts, Yogyakarta, Indonesia

Brain Science and Engineering Innovation Research Group, School of Anti-Aging and Regenerative Medicine, Mae Fah Luang University, Bangkok, Thailand.

Orcid ID:

Dr. Djohan - (D) https://orcid.org/0000-0002-6705-3436

Dr. Fortunata Tyasrinestu - (i) https://orcid.org/0000-0003-3158-3563

Dr. Phakkharawat Sittiprapaporn - (i) https://orcid.org/0000-0002-4103-9396

Source of Support: Ministry of research, technology, and higher education of Indonesia and Brain Science and Engineering Innovation Research Group, Mae Fah Luang University grant (2019) (MFU-grant no. 611U109005) and 2020, Thailand, Conflict of Interest: None. 